\title{
SEMIOLOGIA NEUROPSICOLÓGICA
}

\author{
BEATRIZ H. LEFHVRE * \\ RICARDO NITRINI **
}

A investigação neuropsicológica abrange grande variedade de itens relativos à atividade nervosa superior. Luria 10,11 salienta que cada área cerebral traz uma contribuição altamente especializada que assegura o desempenho de todo sistema funcional. Baseando-se no texto de Christensen 2 é introduzida sistematização do exame neuropsicológico e é apresentada versão simplificada da qualificação dos sintomas, que são correlacionados a estruturas anatômicas cerebrais segundo o conceito de "sistemas funcionais".

\section{SISTEMATIZAÇAOO DO EXAME. CORRELAÇOES CLANICO-ANATOMICAS (CCA)}

1. ENTREVISTA INICIAL - Na primeira abordagem abre-se o caminho para posterior análise. Observam-se o estado de alerta, a atenção, a orientação no espaço e no tempo, a crítica quanto ao estado de saúde, a presença de perseveração, fatigabilidade e o comportamento do paciente. 1.1 Estado de alerta e atenção - Observar o nível de consciência, verificando se há sonolência, obnubilação e se o paciente está atento ao exame. CCA - Distúrbios do nível de consciência refletem alterações localizadas no tronco cerebral, que envolvem a substancia reticular ativadora ascendente ou alterações córtico-subcorticais. Lesões exclusivamente corticais não afetam o nível de consciência, a menos que sejam muito extensas. Desatenção é frequente em lesc̃es frontais e em lesões subcorticais. 1.2 Orientaço no tempo e no espaco - Interrograr sobre a data do exame (hora, dia da semana, do mês, do ano), tempo de doença, local onde se encontra, caminho percorrido até local do exame. Informar-se com familiares sobre orientação espacial na residência e redondezas. CCA - Desorientação no tempo e no espaço acompanham distúrbios do nível de consciência de pouca intensidade o ocorrem também nas lesões corticais difusas, sendo sinais iniciais das demências corticais. Dentre as lesões corticais focais, a desorientação é frequente em lesões dos lobos frontais. 1.3 Escolaridade - Informar-se sobre o nivel cultural e como foi realizada a alfabetização (rural ou urbana, anos de estudo). 1.4 Trabalho e lazer -

Trabalho realizado na Divisão de Neurologia do Hospital das Clínicas da Faculdade de Medicina da Universidade de São Paulo (FMUSP): * Psicóloga da Unidade de Psicologia do Instituto Central do Hospital das Clínicas, responsável pelo Setor de Psicologia da Divisão de Neurologia desse Hospital; ** Professor Assistente de Neurologia do Departamento de Neuropsiquiatria da FMUSP. 
Indagar sobre a profissão, práticas esportivas e outras atividades. 1.5 Atitude diante da doensa - Indagar sobre a queixa principal e sobre outros sintomas. Investigar a crítica a sua memória, fala, escrita, leitura e as dificuldades de sensibilidade geral e especial. CCA - Pacientes com lesão do hemisfério cerebral direito apresentam, trequentemente, agnosia dos distúrbios. Mesmo quando estes são reconhecidos, o. paciente não lhes dá a importancia devida. comum que pacientes com agnosias tentem justificar suas dificuldades atribuindo-as a distúrbios elementares. Nas lesões frontais a crítica quanto ao próprio estado de saúde é muito comprometida. 1.6 Comportamento - Observar a atitude, apresentação pessoal, colaboração. Informar-se sobre seli comportamento diário, afetividade, comportamento sexual, presença de alucinaçóes. CCA - As alteraçóes do comportamento social ocorrem frequentemente em lesões das porçóes orbitárias do lobo frontal e nas que envolvem as porções mesiais dos lobos temporais, que fazem parte do sistema límbico. O comportamento órbito-frontal acarreta acentuação da desinibição. Manifestam-se então perda de autocontrole, crises emocionuis violentas e alteraçôes grosseiras de caráter que refletem impulsidade incontrolável. A presença de alucinaçōes, especialmente olfativas e gustativas, sugere lesões temporais profundas. Quando existem alterações concomitantes da afetividade, 6 ainda maior a probabilidade de lesão nessas regióes.

2. DOMINANCIA HEMISFrRICA - Para o exame da dominancia manual, solicitar que o paciente imite atividades da vida diária, como os atos de comer, escovar os dentes, cortar o pão e escrever. A dominancia ocular pode ser pesquisada segundo as provas descritas no Exame Neurológico Evolutivo (WNG) s com a técnica do cartão perfurado. Inicialmente o paciente segura o cartăo com ambas as mãos, em seguida com a mão contralateral ao olho inicialmente escolhido e por fim com a outra mão. Para a dominancia dos membros inferiores, pede-se que chute várias vezes uma pequena bola, buscando atingir um alvo.

3. FUNCAO MOTORA - 3.1 Fruncão motora das mãos - 3.1.1 Movimentos simples: oponência entre polegar e demais dedos, realizadas simultaneamente com as duas mâos. Observar fadiga, perseveração, assimetrias. O examinador senta-se em frente ao paciente a pede que reproduza posições dos deđos e das mãos do examinador. CCA - Imagens em espelho (por exemplo, estender o dedo mínimo quando deveria estender o indicador) sugerem lesão frontal. Inércia patológica, caracterizada pela dificuldade em passar de um movimento a outro, ocorre em lesర̃es das divisões corticais anteriores (córtex prémotor e córtex frontal). 3.1.2 Base cinestésica do movimento: imitar com uma ias mãos as posições da outra; sem controle visual. CCA - Nas lesões do córtex pós-central contralateral ou de suas vias aferentes, a imitação é incorreta quando o controle visual é bloqueado, porque a sensibilidade cinético-postural está comprometida (apraxia cinestésica aferente). 3.1.3 Organização ótico-espacial: movimentos da mão no plano horizontal, frontal e sagital; gestos das mãos formando ângulos (Fig. 1). CCA - As áreas parietais inferiores e parieto-occipitais estão frequentemente afetadas quando há desurganização óptico-espacial. 3.1.4 Organização dinamica: movimentos alternados e simultâneos de abrir uma das mãos e fechar a outra; bater a mão direita na mesa duas vezes e a mão esquerda uma vez, em sequência; inverter, batendo duas vezes com a mão esquerda e uma vez com a direita; sequência de 3 posiçőes da mão batendo na mesa (Fig. 2): mão pronada com dedos estendidos, mão pronada com dedos fletidos e 
mão na vertical com dedos estendidos. Copiar desenho com dois componentes alternados sem tírar o lápis do papel. CCA - Distúrbios na organização dinâmica geralmente refletem lesões das divisões corticais anteriores. A coordenação recíproca de ambas as mãos também pode ser afetada em lesões do corpo caloso. Nas lesões corticais anteriores há dificuldade de passar de um movimento a outro e de inibir movimentos após seu início. Nas lesões pré-motoras o paciente percebe seus erros e tenta corrigi-los enquanto nas lesões frontais a crítica não está preservada. Ordens verbais melhoram o desempenho quando há lesões pré-motoras, mas não o modificam em lesões frontais. 3.2 Formas complexas de praxias - Praxia ideatória: servir café, enfiar linha na agulha, abotoar, isar martelo. 3.3 Praxia oral - 3.3.1 Movimentos simples da língua, lábios e face: observar desvios, assimetrias, sincinesias. 3.3.2 Base cinestésica do movimento: protrair a língua, rolar a língua pelos lábios, colocar a língua entre os dentes

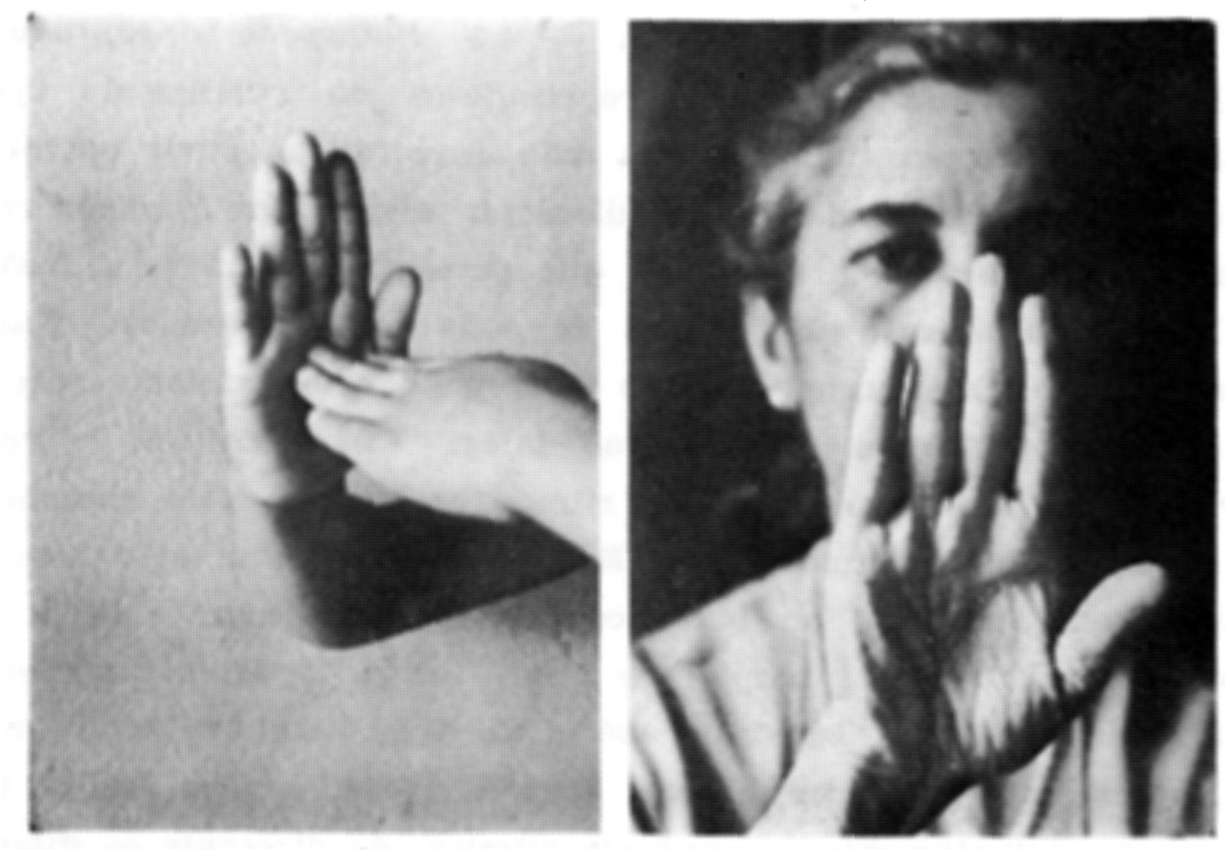

Fig. 1 - A esquerda, organização bptico-espacial com gestos das mãos formando angulos. A direita, movimentos das mãos no plano horizontal, frontal e sagital que o paciente deve imitar.

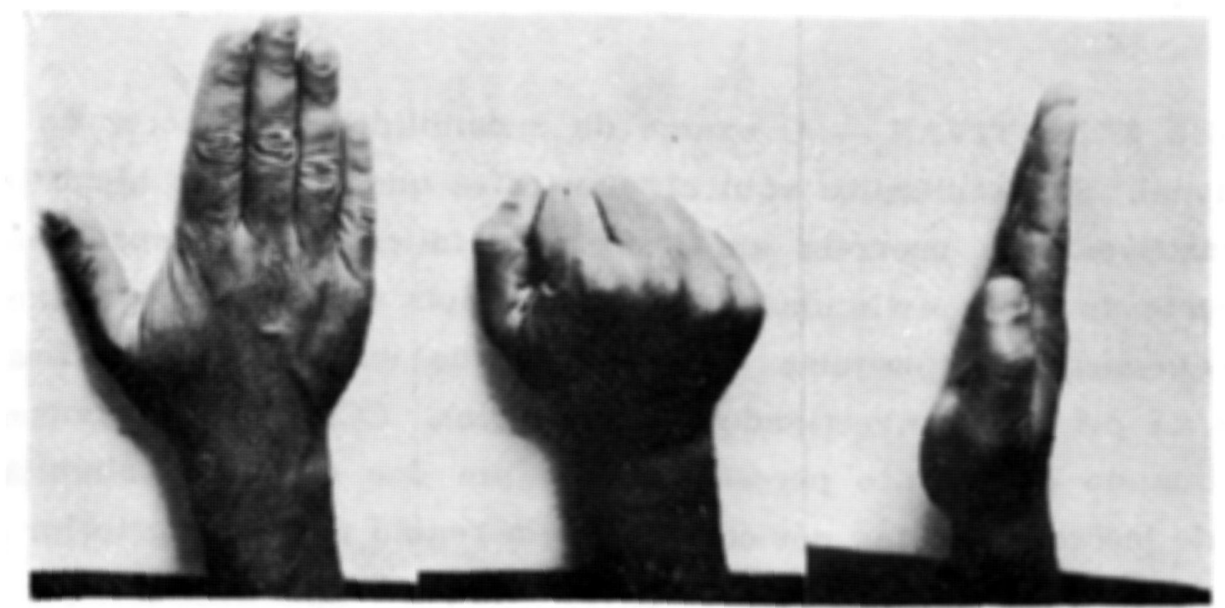

Fig. 2 - Organizacão dinamica: movimentos alternados e simultâneos com sequencia de três posigőes. 
e o lábio superior. CCA - Está afetada nas lesões das porç̃es inferiores do córtex pós-central (apraxia cinestésica aferente). 3.3.3 Organização dinamica: movimentos repetidos e em sucessão. CCA - Nas lesões pré-motoras há dificuldade de passar de um movimento para o outro. 3.3.4 Praxia oral integrativa: mastigar, assobiar, assoprar. CCA - Estes testes servem para demonstrar distúrbios mais leves da praxia oral. Como são movimentos complexos podem ser afetados por lesões em sítios diversos. 3.4 Regulação do ato motor pela fala - Desenhar círculo, cruz e quadrado em sequência. Bater duas vezes em resposta a uma batida e uma vez em resposta a duas batidas, ou levantar a mão direita em resposta a um sinal e levantar a mão esquerda em resposta a dois sinais. CCA - Perseverações e respostas ecopráxicas ocorrem em lesões frontais. Em lesões temporais o paciente não retém perfeitamente a ordem verbal. Em lesões frontais severas o paciente retém as instrucões, é capaz de repeti-las mas seus movimentos não obedecem às ordens verbais.

4. ORGANIZAÇAO ACOSTICO MOTORA - 4.1 Percepgão $e$ reproduço de sons musicais - Distinguir altura dos sons, repetindo-os ou sinalizando (por exemplo: levantar a mão direita ao ouvir um som e a mão esquerda ao ouvir outro). Identificar melodias simples. CCA - Dificuldade em discernir altura dos sons ocorre em. lesñes das regiōes temporais. Na amusia sensorial, que geralmente se deve a lesões temporais direitas, não há reconhecimento de grupos de sons e de melodias. Nas lesões das divisões corticais anteriores, a repetição dos sons pode estar afetada pela presença de perseveração, que também se manifestará ao falar. 4.2 Percepsão e reproducão de estruturas rítmicas - 4.2.1 Reprodução de ritmos executados pelo examinador: podem ser utilizadas a sequência de ritmos do ENE 5 devendo acertar pelo menos 4 estruturas, apresentadias com anteparo, ao bater com o lápis na mesa: 1) ooo; 2) o oo; 3) 0000 ; 4) $00 \quad 00$; 5) $0 \quad 0 \quad 0$; 6) $00 \quad 0 \quad$ o. 4.2 .2 Executar ritmos após instrucões verbais: «série de duas batidas», «série de três batidas», «duas batidas fortes e três fracas», «três batidas fracas e duas fortes». CCA - Em lesões temporais há dificuldade de repetir corretamente a sequência ritmica, de discernir os diferentes ritmos e de perceber o número de batidas. Nesses casos os ritmos são melhor executados sob ordem verbal. Em lesões pré-motoras não há dificuldade em reconhecer as diferentes estruturas rítmicas, mas a repetição é prejudicada pela presença de perseveração. Em lesões frontais, como a regulação do ato motor pela fala está comprometida, a reprodução após instrução verbal é mais difícil que a repetição dos ritmos executados pelo examinador.

5. FUNÇOES SENSITIVAS - O exame da sensibilidade faz parte do exame neurológico convencional. São analisados aqui alguns testes que permitem identificar distúrbios de funções sensitivas que ocorrem em lesões encefálicas. 5.1 sensibilidade tdictil Identificar a parte do corpo estimulada; identificar dois estímulos simultaneos em pontos simétricos dos hemicorpos (pesquisa do fenômeno de extinção); identificar números e letras traçados na pele pelo investigador (grafestesia). CCA - O fenômeno da extinção está presente quando o paciente percebe apenas um dos estímulos simultaneos. Geralmente decorre de lesões do córtex pós-central ou da região parietal posterior contralaterais ao hemicorpo em que o estímulo não é percebido. A agrafestesia é de interpretaçăo complexa. Pode refletir distúrbios sensitivos ou das conexões parieto-temporais. 5.2 Estereognosia - Nomear ou identificar formas ou objetos familiares através do 
tato (Fig. 3). CCA - Lesões parietais contralaterais causam astereognosia. Em lesões das conexões parieto-temporais pode haver identificação do objeto mas impossibilidade de nomeá-lo.

6. PERCEPÇÃO VISUAL - $O$ exame neuropsicológico sempre deve ser precedido por investigação neuro-oftalmológica para que distúrbios dos aspectos mais elementares da função visual não prejudiquem ou invalidem as conclusões da avaliação neuropsirológica. 6.1 Objetos e figuras - Objetos e figuras comuns. Figuras mal definidas ou incompletas. CCA - Nas lesóes das áreas do córtex visual secundário, o paciente é incapaz de combinar as impressões e de integrá-las para a percepção do todo. Nesta situação, denominada agnosia óptica, é frequente que o pacientè identifique prematuramente as imagens, a partir da visão de um fragmento. Negligência do hemicampo visual esquerdo ocorre frequentemente em lesões das porções posteriores do hemisfério cerebral direito. 6.2 Orientagão espacial - Distinção entre direita e esquerda. Posições dos ponteiros do relógio: identificar principais aspectos de um mapa. Reproduzir formas com bastões ou palitos. Cópia de desenho com lápis e papel. CCA - Em lesões parieto-occipitais e das regióes parietais inferiores há dificuldade em distinguir direita de esquerda, leste de oeste e figuras que sejam imagens especulares (por exemplo, ponteiros indicando 9 horas ou 3 horas). 6.3 Operacóes intelectuais no espaco - Copiar formas com cubos coloridos de Kohs. Formas simples (por exemplo, dois cubos vermelhos na parte de cima do quadrado e dois brancos na parte de baixo) ou mais complexas (formas com linhas inclinadas (Fig. 3). Construir com cubos ou com formas tridimensionais de
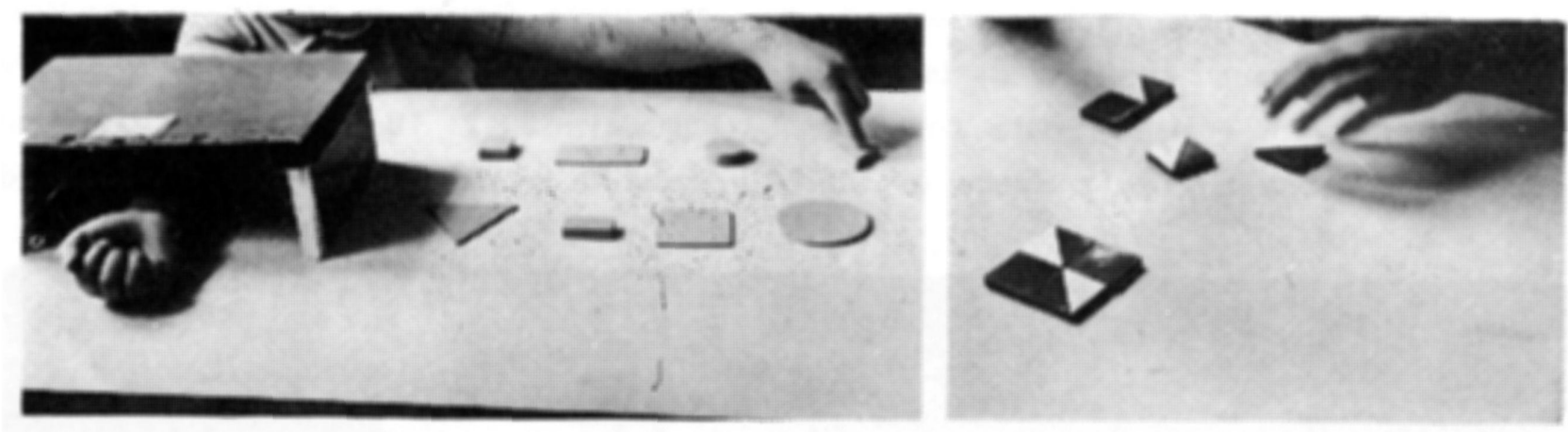

IFig. 3 - A direita, exame da estereognosia: o paciente deve apontar a forma semethante sem o controle visual da mão que segura a forma. A esquerda, operacão intelectual no espaco com os cubos de Kohs dados com linhas imclinadas.

madeira, sob instrução verbal ou copiando de um modelo apresentado. CCA - Esses testes analisam as operações intelectuais no espaço, a função visual e as habilidades construtivas. importante verificar se as dificuldades decorrem de incapacidade de análise visual do modelo, o que sugere lesão parieto-occipital, ou se decorrem de dificuldade para programar as operações sucessivas, o que caracteriza as lesões frontais.

7. FALA RECEPTIVA - 7.1 Audigĩo fonêmica - 7.1.1 Repetir: fonemas isolados $(\mathrm{O}, \mathrm{A}, \mathrm{P}, \mathrm{B}, \mathrm{M}, \mathrm{D}, \mathrm{K})$; pares de fonemas diferentes (B-N, P-S, F-K); pares de fonemas semelhantes acusticamente (B-P, D-T, G-K); pares de fonemas de articulação semelhante (M-P, N-D, D-L-T); séries de fonemas (A-O-A, M-S-D, B-R-K); séries de fonemas semelhantes (B-P-B, P-B-P, D-T-D, T-T-D); séries de consoantes idênticas 
com vogais diferentes (BI-BA-BO, BO-BI-BO). Para diferenciar os casos que apresentam dificuldades de discriminação auditiva daqueles em que há distúrbios de expressão, solicita-se ao paciente que escreva ou que aponte para letras colocadas à sua frente ou ainda, que reaja de modo diferente aos sons (por exemplo, «se ouvir B levante a mão direita e se ouvir $P$ levante a mão esquerda»). CCA - Lesão das áreas secundárias do córtex auditivo, no lobo temporal esquerdo, reduz a capacidade de discriminação de fonemas acusticamente semelhantes. Segundo Luria, esta é a alteração fundamental da afasia sensorial. Dificuldade em distinguir fonemas de sons diferentes, mas de articulação semelhante, pode ocorrer em lesões situadas na porção inferior do córtex pós-central do hemisfério cerebral esquerdo. Nesses casus há comprometimento da propriocepção dos órgãos envolvidos na articulação dos fonemas, o que caracteriza a afasia motora aferente ou afasia cinestésica. Nas lesões das divisões corticais anteriores do hemisfério cerebral esquerdo há dificuldade em repetir, mas a distinção entre os fonemas é corretamente realizada. 7.2 Compreensão das palavras - 7.2.1 Definir ou apontar objetos como lápis, mesa, cadeira, porta ou partes do corpo como nariz, boca, ombro, testa. 7.2.2 Compreensão de séries de palavras: «apontar o lápis, c papel e a porta" ou "mostrar o nariz, a boca e o olho". 7.2.3 Identificação de figuras. CCA - Na afasia sensorial, a compreensão de palavras está comprometida porque a discriminação fonêmica é incorreta. Nas lesões das porções médias do lobo temporal esquerdo (área 21 de Brodmann) ou em lesões temporais profundas, ocorre a afasia acústico-mnéstica. Nesta forma de afasia, as palavras são compreendidas quando pronunciadas isoladamente mas há dificuldade para a compreensão de série de palavras porque a memória audio-verbal encontra-se alterada. 7.3 Compreensão de sentenças - 7.3.1 Instruções simples: "abra a boca", "feche os olhos", "mostre nesta figura a panela, a tesoura". Instruções complexas: «mostre nesta figura o que serve para a sopa», «r. que traz segurança", "o que é usado pela costureira" (Fig. 4). 7.3.2 Instruções verbais mais longas, como "abra a boca e feche os olhos", "coloque o lápis em baixo da folha de

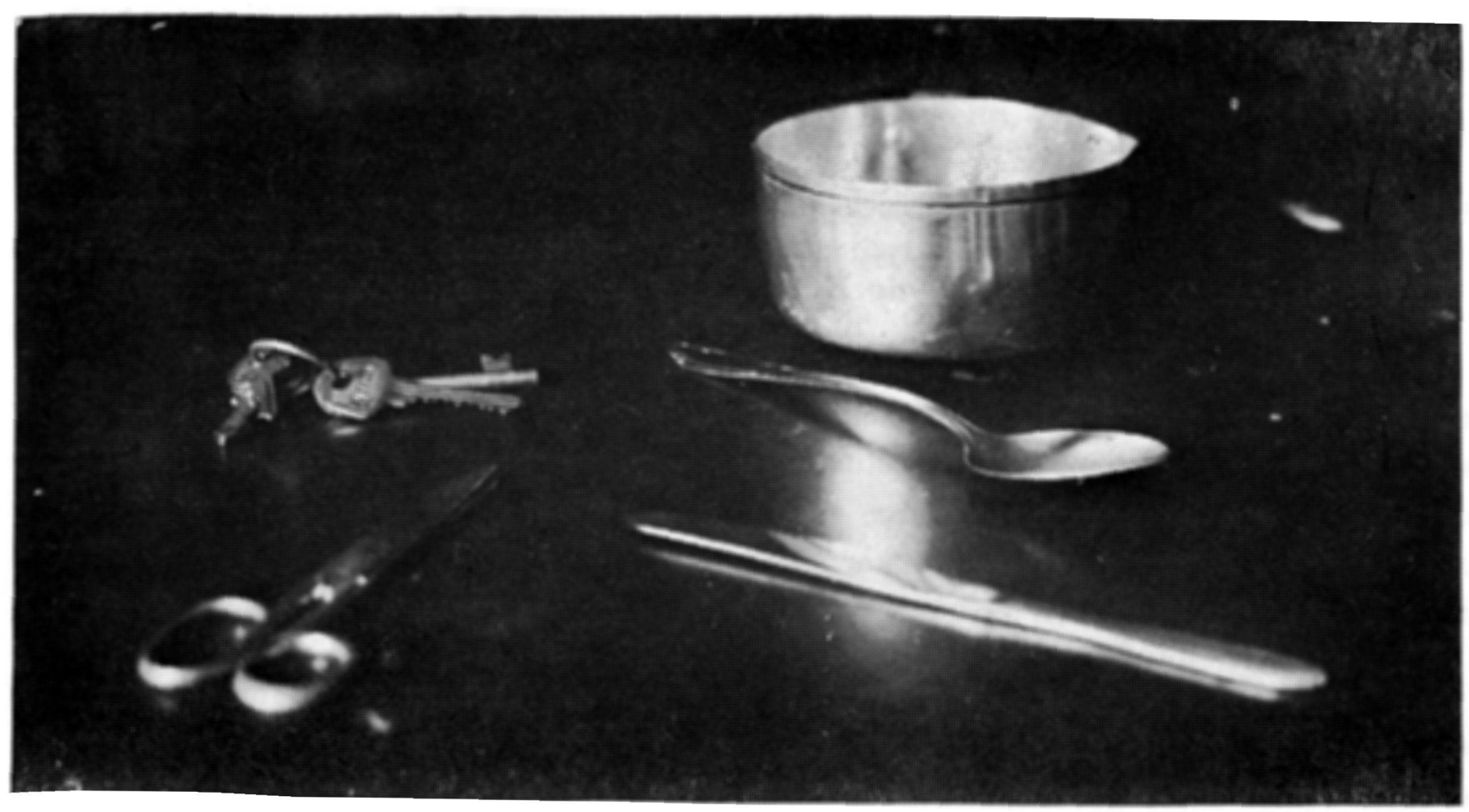

Fig. 4 - Compreensão de sentengas simples e complexas como "mostrar a chave" ou "mostrar o que tras seguranca". 
papel". 7.3 Instrução conflitiva: "veja este cartão cinza e este cartão preto; se agora for noite aponte o cinza e se for dia aponte o cartão preto". CCA - A compreensão de sentenças requer obediência a regras gramaticais e capacidade de inibir conclusões prematuras, além da faculdade de compreender as palavras e de retê-las na memória. Nas lesões frontais oư nas lesões generalizadas há grande dificulade em inibir conclusões imediatas. 7.4 Construç̃o simples - 7.4.1 Três objetos são colocados à frente do paciente, como: uma régua, um lápis e uma tesoura. Solicita-se ao paciente que aponte o lápis ou a régua. Solicita-se então que kaponte a réguz com o lápis» e em seguida que «aponte com a régua para o lápis», ou «aponte com a tesoura o lápis». 7.4.2 Relações espaciais: identifique ou desenhe um triangulo dentro de um círculo, um cículo dentro de um triângulo (em cima, ao lado). 7.4.3 Construções comparativas: «que menino é menor, se João é mais alto do que Pedro?; «qual menina é mais clara se Ana é mais clara que Helena mas e mais escura que Olga?». 7.4.4 Construçáo gramatical invertida; «o que eu fiz primeiro se tomei café depois de calçar o sapato?»; «o irmão do pai e o pai do irmão são a mesma pessoa?». 7.4.5 Estrutura gramatical complexa: «a mulher que trabalhava na fábrica veio até a escola onde Maria estudava para entregar a encolnenda. Quem entregou a encomenda? o que Maria estava fazendo?». CCA - A compreensão de estruturas lógico-gramaticais complexas depende, além das faculdades já mencionadas, que permitem a compreensão de sentenças simples, de duas outras condições essenciais. A primeira delas é a capacidade de síntese simultanea dos elementos da frase e que se encontra afetada na afasia semantica. Esta forma de afasia resulta de lesões parieto-occipitais ou têmporo-parieto-occipitais esquerdas. A segunda condição é a capacidade de realizar uma análise ativa dos elementos mais significativos e de impedir conclusões prematuras. Esta capacidade é muito afetada nas lesóes frontais.

8. FALA EXPRESSIVA - 8.1 Articulacão de sons - Repetir: A, I, M, B, CH, PR, CL, FR, STR, VR, DR, VIU-VIR, SOU-SOL, PAO-SAO, PALA-PELO, PANO-PANE, BRIGA-GRITA, PRETO-PERTU, GALO-CALO, QUARTO-PRATO-FRACO, DADO-CABO-LADO, FEIXE-LENTE-DENTE, LA - DA - TA - NA. Observar a pronúncia, clareza e a intensidade dos sons. Quando houver dificuldade, o paciente pode tentar melhorar a articulação utilizando-se de um espelho. Ao auxiliar o paciente a articular melhor, o examinador tem oportunidade de descobrir quais os distúrbios articulatórios predominantes. CCA - Na afasia sensorial há dificuldade na repetição de fonemas acusticamente semelhantes enquanto na afasia motora aferente são os fonemas com articulạcōes semelhante os de repetição mais difícil. Nesta última, o emprego de espelho pode melhorar um pouco o desempenho. Nas lesões da porção inferior da área pré-motora do hemisfério cerebral esquerdo (afasia motora eferente ou cinética) existe inércia patológica que dificulta a passagem de um fonema para outro, ocorrendo perseveração. 8.2 Frala repetitiva - 8.2.1 Repetição de palavras: casa, gato, pacote, triste, rinoceronte, metalúrgico, ingrediente, desengonçado, Pindamonhangaba, familiaridade. CCA - Pacientes com lesões severas do lobo temporal esquierdo não compreendem e não repetem as palavras. Ocorrem parafasias que podem ser fonêmicas, silábicas ou verbals. 8.2.2 Repetição de série de palavras: casa-pino-conta; pino-casa-conta; conta-casa-pino. 8.2.3 Repetição de trases: "hoje não está chovendo", "no mesmo dia em que. ele comprou o carro, deu uma batida". "a mangueira cresceu na horta, atrás da cerca de arame farpado", "a casa pegou fogo, a lua brilha no céu, a chuva pinga no telhado" (modificar a ordem das orạ̧óes). CCA - Nas lesões das porções médias da 
convexidade temporal ou nas lesões temporais profundas do hemisfério cerebral esquerdo, - paciente consegue lembrar-se apenas das primeiras palavras da série, porque há distúrbios da memória audioverbal. Na afasia transcortical motora, que decorre de lesão situada anterior ou superiormente à área de Broca, observa-se perseveração quando o paciente tenta passar de uma palavra a outra, sendo que cada palavra é bem pronisnciada isoladamente. 8.3 F'unção nominativa da fala - 8.3.1 Nomear objetos e figuras: mostrar objetos familiares, figuras, partes do corpo humano. CCA - Para correta nomeação de objetos e de figuras há necessidade de identificação das características que permitem seu reconhecimento visual. Nas lesões têmporo-occipitais esquerdas há dificuldade de reconhecer os objetos e de desenhar a forma de objetos nomeados: Em tais casos, se o examinador fornece a primeira sílaba, a nomeacão é facilitada. Nas lesões adjacentes a área de Wernicke e na afasia sensorial em fase de regressão, as pacientes não conseguem designar os objetos porque os traços auditivos estão mal preservados. Não há melhora se o examinador tenta auxiliar dizendo as sílabas iniciais. Em formas menos severas surgem parafasias (por exemplo, mata por mapa). Ao tentar nomear um objeto, ocorrem muitas alternativas, das quais uma deve ser isolada e as demais rejeitadas. Por exemplo, um «cão» pode ser nomeado como animal, quadrúpede, carnívoro, mamiferạ, ou pela sua raça. Em lesões da encruzilhada têmporo-parieto-occipital esquerda, o paciente evoca um número excessivo de alternativas e é incapaz de selecionar a mais adequada. Em lesões próximas à área de Broca e, mais especialmente, em lesões da região fronto-temporal esquerda, ocorrem perseverações. Assim, após nomear um objeto, haveré tendência a nomear os outros objetos que lhe forem apresentados, repetindo a mesma palavra. 8.4 Frala warrativa - 8.4.1 Fala automatizada: contar de 1 até 10; dizer os dias da semana e os meses do ano (na ordem direta e na ordem inversa). CCA - Nas lesões das divisões corticais anteriores há dificuldade em recitar as sequências porque a fala é pouco fluente e repleta de perseveraçóes. Nas lesões temporais as séries automatizadas são repetidas com certa facilidade mas, quando devem ser ditas em ordem inversa, a tarefa torna-se quase impossivel. De fato, em todas formas de afasia, é possivel notar melhor desempenho em atividades automatizadas. 8.4.2 Fala predicativa: Perguntar sobre o que fez durante o dia, o que almoçou, o que fez nas férias, o que está acontecendo em uma figura. Solicitar que o paciente conte alguma coisa sobre assunto de interesse dele (trabalho, esportes, programas de televisão, família), ou que repita uma estória (por exemplo: «ontem, Pedro, que tem ? anos, foi pescar no rio. Ele levou seu cachorro Fiel. O rio tinha subido por causa da chuva. Pedro escorregou e caiu no rio. Ele teria morrido afogado se o cachorro não tivesse mergulhado e o ajudado a chegar à margem»). CCA - A presença de inércia patológica, manifestada por perseverações fonêmicas na afasia motora eferente e por perseverações verbais na afasia transcortical motora, dificulta bastante a fala predicativa. Na afasia transcortical observa-se estilo telegráfico. A fala espontanea é bastante comprometida em lesões das porções posteriores da convexidade frontal ou em lesões fronto-temporais que poupam a área de Broca. Essas lesões causam a afasia dinâmica. Segundo Luria, a pobreza da fala espontanea, registrada em tais casos, reflete distúrbios da linguagem interna. Há grande dificuldade em repetir estórias.

9. ESCRITA E LEITURA - 9.1 Análise e sintese fonemicas - 9.1.1 Análise: dizer o número de letras da palavra «GATO»; dizer a segunda letra das palavras GATO, CHAVE, TRAPO; dizer a letra que se segue ao «L» na palavra CALMO. 9.1.2 Síntese: indicar 
que sílabas ou palavras são formadas pelas letras «D» mais «O»; «P» mais «O» mais $\ll R » ; \ll P \gg$ mais «E» mais «D» mais «R», mais «A»; $P$ mais $f ;$ mais $E$ mais $D$ mais $O$. CCA - A análise 6 muito comprometida em lesões temporais pela impossibilidade de discriminação auditiva correta dos fonemas. O paciente não consegue determinar sequer o número de letras das palavras. Na afasia motora aferente há condicões de informar - número de letras mas a identificação dos sons é prejudicada porque a articulação é deficiente. Em lesões frontais ou fronto-temporais esquerdas há dificuldade nos testes de sintese de fonemas. Observa-se incapacidade de inibir conclusões apressadas. Tem-se a impressão que o paciente procura adivinhar a palavra ou a sílaba em questão. Pacientes com lesões infero-parietais ou têmporo-parieto-occipitais esquerdas têm dificuldañe em realizar testes de síntese de palavras porque não conseguem avaliar a posição dos fonemas. Não há entretanto distúrbios da compreensão ou da articulação das palavras. 9.2 Escrita - Escrever o nome e o endereço. Escrever sob ditado: F, T, H, L, BA, DA, TA, NA, LA, FIGO, VIDRO, CRIANGA, CABRITO, GALINHA, FAVO, VALE, PATO, PITO, TRONCO, CHAPEU, INGREDIENTE, PLANTAÇA, FISIOLOGIA, BICICLETA, CONSTITUIÇAO, TRABALHO, CHAVE DE FENDA, PAR DE MEIAS, LUA CHELA. Escrever um recado. Copiar palavras e frases (T, M, F, DA, BO, PORTA, O CAVAlo GalopoU.). CCA - Na afasia sensorial e na afasia motora aferente, em que a discriminação dos fonemas é imperfeita, a escrita sob ditado mostra-se bastante alterada, enquanto a cópia e a escrita de palavras familiares encontram-se normais. Paragrafias são mais intensas na afasia sensorial. Na afasia motora eferente, o paciente escreve letras ditadas isoldamente mas tem dificuldade de escrever silabas complexas cu palavras, devido à presença de inércia patológica. Ocorrem perseverações que também se manifestam durante a cópia. Em lesões occipitais, têmporo-occipitais e parieto-occipitais esquerdas, as letras são escritas erradamente, com suas linhas em posições espaciais erradas ou construídas como imagens especulares. Estes erros também ocorrern durante a cópia, embora com menor intensidade. O distúrbio básico, em tais casos, é a instabilidade das conexões auditivo-visuais que acarretam um tipo de apraxia construtiva. possível observar que a construção ou desenho de figuras ou objetos mostrem-se bastante alterados, especialmente quando realizados «de memória», sem auxilio de modelo. Perseveração, fadiga rápida e micrografia (redução progressiva do tamanho das letras) ocorrem frequentemente em lesões frontais. 9.3 Leitura - Identificar letras. Leitura de sílabas e palavras: PRO, CRA, COR, FLE, FOGO, DEDAL, FERRAMENTA. Leitura de siglas: CIC, INPS, CEP. Leitura de palavras complexas: MACROMOLECULAR, EPISTEMOLOGIA. Leitura de frasea: «Pelé chutou a bola na trave», «o sol brilha de noite e a lua de dia», «a formiga não é menor do que o elefante». Leitura de textos. CCA - Em lesões occipitais esquerdas ocorre alexia óptica, em que são confundidas letras de formas semelhantes como m e $n, g$ e $q, b$ e d. Em lesões pariet:o-occipitais esquerdas, o paciente reconhece as letras individualmente mas năo consegue ler as palavras ou as siglas. Nessas condições ocorre simultâneo-agnosia, havendo dificuldade na percepção concomitante de dois ou mais objetos. Negligência da metade esquerda das palavras ou do texto sâo encontradas em lesões do hemisfério central direito, principalmente quando há comprometimento do lobo parietal. A leitura de palavras escritas verticalmente é realizada com facilidade. Na afasia sensorial, a leitura de palavras e siglas muito comuns pode ser realizada, mas a leitura torna-se impossível quando é necessária análise acústica dos fonemas. A leitura em voz alta é ainda mais 
dificil. Na afasia motora eferente há dificuldade para a leitura em voz alta, devido aos distúrbios de expressão.

10. HABILIDADE PARA O CALCULO ARITMÉTICO - 10.1 Compreensão da estrutura do número - Reconhecer símbolos numéricos. Escrever e ler algarismos arábicos e romanos. Dizer o número de objetos (ou de dedos) que lhe forem apresentados. Escrever números com muitos dígitos. Escrever números verticalmente. Identificar o número maior e o menor de um conjunto de números. CCA - Em lesões do córtex visual secundário há dificuldade no reconhecimento visual do símbolo gráfico dos números, mas o conceito de número está preservado. O paciente consegue identificar o número de objetos pelo tato ou é capaz de compreender quando os números sĩo expressos oralmente. Na afasia sensorial há dificuldade na decodificação auditiva que pode prejudicar a compreensão dos números quando são expressos oralmente. A compreensão de algarismos romanos e de números com muitos dígitos está muito afetada nas lesões ínfero-parietais, parietais e parieto-occipitais. Nesses casos há grande dificuldade em identificar a categoria de um dígito em função de sua posição no número. 10.2 Operaçóes aritméticas - Fazer cálculos simples e operações aritméticas mais complexas oralmente ou por escrito: $(3+1),(5 \times 9),(31-7),(41-14)$. Preencher com os sinais que faltam: $(10 \quad 3=7,(9 \quad 4=13),(10 \quad 2=5),(10 \quad 2=20)$. CCA - Os distúrbios mais intensos de cálculo ocorrem nas lesões infero-parietais ou parieto-occipitais esquerdas devido à desintegração da sintese visuo-espacial e nas lesões ou disfuncões cerebrais difusas. Nas lesões frontais, os cálculos simples podem ser efetuadiss, mas durante a realização de operações mais complexas manifetam-se perseverações, estereotipias e conclusões prematuras devido à desinibição.

11. PROCESSO MNASTICO - 11.1 Processo do aprendizado - Repetícão de conjunto de palavras. Informar que como serão muitas palavras será difícil lembrar-se de todas na primeira vez. Nível secundário: «casa, boi, pão, noite, sino, luz, ponte, mesa, pé, chuva». Indagar qual o número de palavras que o paciente julga que será capaz de lembrar. Nivel de pacientes semi-alfabetizados ou analfabetos (teste ABC de Lourenço Filho 9): «árvore, cadeira, pedra, cachorro, flor, casa, peteca». As séries de palavras podem ser repetidas até 10 vezes. Gráficos podem auxiliar na análise. CCA - Pacientes com lesões em áreas cerebrais posteriores ou com distúrbios cerebrais difusos prestam atenção às palavras e procuram não cometer os mesmos esquecimentos em repetições sucessivas. Nas lesões frontais há repetição de baixo número de palavras e falta de crítica quanto a suas possibilidades. As palavras são repetidas de modo estereotipado, repetindo os mesmos erros sem tentar corrigi-los. 11.2 Retenção e evocação - 11.2.1 Reconhecimento de formas. Observar uma figura simples, como um triangulo ou um quadrado durante 5 segundos e lembrar-se 30 segundos" depois. 11.2.2 Reproduça imediata de estímulos visuais, acústicos, cinestésicos e verbais. Solicita-se ao paciente que reproduza figuras e ritmos, posições das mãos, ou que repita palavras, frases e estórias. Inicialmente o examinador não preenche o intervalo entre o estímulo e sua reprodução mas posteriormente o preenche com interferência heterogênea (estímulos de modalidade diferente da testada) ou interferência homogenea (estímulos de mesma modalidade da testada). O Intervalo deve variar de 30 segundos a 1 minuto e meio para a reprodução imediata. A capacidade de fixação ou de consolidação é avaliada observando-se se o paciente é capaz de reter dados por tempo superior a 2 minutos e 
interrogando-o sobre eventos recentes («como chegou ao hospital?», «que comeu na última refeição?», «como estava o tempo hoje cedo?»). CCA - A reprodução imediata encontra-se bastante alterada quando o paciente está sonolento ou confuso, refletindo comprometimento funcional ou orgânico das estruturas responsáveis pela manutenção. do tono cortical. Nessas condições as dificuldades manifestam-se indiferentemente da modalidade do estímulo. Dificuldades específicas para a reprodução de estímulos acústicos e de estímulos vísuo-espaciais podem ocorrer em lesões situadas no córtex temporil esquerdo e nas regiões occipito-parietais, respectivamente. $O$ emprego de interferência presta-se para revelar formas mais leves de distúrbios que não são percebidos com intervalos livres. Lesões bilaterais da face interna do lobo temporal que envolvem us hipocampos causam amnésia de fixação que não se acompanha de confabulação. A așociação de amnésia de fixação e confabulação sugere lesão dos corpos mamilares, núcleos dorsomedianos do tálamo ou das porções mesiais ou fronto-orbitárias dos lobos frontais. Nas lesões frontais a amnésia não é tão intensa quanto nas demais. Memoria lógica -São apresentadas cerca de 12 a 15 palavras impressas em cartões. Em seguida, o paciente deve associar cada palavra a uma de 15 a 20 figuras. A associação é feita livremente. Ao se reapresentar a figura, o paciente deve dizer a palavra correspondente. CCA Este teste investiga também a atividade intelectual do paciente. Os distúrbios mais severos ocorrem em lesões cerebrais difusas. Em lesões frontais, a visão desencadeia associações irrelevantes. Há dificuldade em formar conexões lógicas e em torná-las estáveis.

12. PROCESSO INTELECTUAL - 12.1 Compreensão de quadros temáticos Descrever uma gravura. Formar uma estória em quadrinhos na sua sequência lógica (Fig. 5). CCA - Em lesões cerebrais generalizadas, como na demência de Alzheim૯rr,

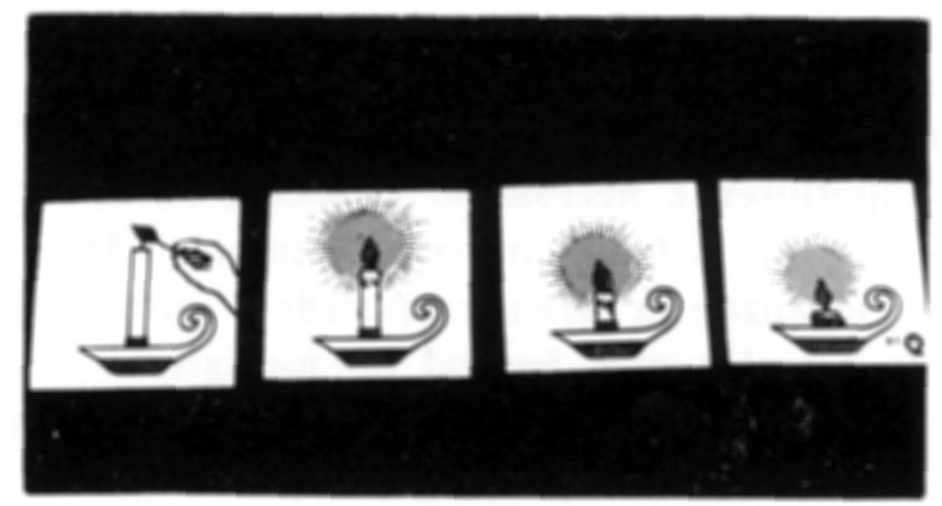

Fỉg. 5 - Compreensão de uma estoria em quadrinhos, na sua sequência lógica. Os cartões devem ser apresentados incorretamente.

ou nas oligofrenias, os pacientes conseguem descrever apenas os elementos, mas nâo compreendem as conexões entre eles e o tema geral. Dificuldades intensas ocorrem nas lesões que causam agnosia visual e, particularmente nas lesões paríeto-occipitais bilaterais que acarretam simultâneo-agnosia. Nestas condições, o paciente não consegue fazer sintese do tema porque a percepção dos diversos elementos ao mesmo tempo é impossível. Em lesões frontais, a análise da figura é realizada de modo fragmentado e a conclusão é atingida apressadamente. $O$ paciente não tem critica sobre seu desempenho. Nas afa- 
sias, principalmente na afasia dinâmica, a descrição do tema é muito pobre, embora a compreensão da figura possa ser normal. 12.2 Interpretą̧ão de refrões e provérbios - Exemplos: "pão-duro"; "coração de pedra"; dedo-duro"; "cara de pau"; "nem tudo que reluz é ouro"; "quem com ferro fere com ferro será ferido"; "cão que late não morde"; "de grão em grão a galinha enche o papo". 12.3 Frormação de conceitos 12.3.1 Definir: envelope, trator, mesa. 12.3.2 Semelhanças e diferenças, como entre «bicicleta e automóvel», «pássaro e avião», «bola e laranja». 12.3.3 Classificação em categorias - Relacionar objetos que podem ser classificados, como "móveis, ferramentas, meios de transporte". Exemplo: "Nestas figuras que elementos não pertencem ao grupo?". 12.3.4 Conceitos opostos: “doença, alto, bom, feio, jovem ou criança, pequeno, em balxo". CCA - Nas lesões orgânicas cerebrais há tendência a interpretação concreta dos refrões e provérbios, com redução da capacidade de abstração e de generalização. As maiores dificuldades ocorrem nas lesões difusas e nas lesões frontais. 12.4 Atividade intelectual discursiva - 12.4.1 Problemas aritméticos elementares, como «Pedro tem 3 laranias e João tem 6 laranias: quantas eles têm juntos?». 12.4.2 Problemas complexos, como: «Maria tinha 4 laranjas e Ana tinha 2 a mais do que Maria; quantas laranjas tinham juntas?», «o colono foi à cidade a pé em 15 minutos; outro homem foi a cavalo e chegou 5 vezes mais depressa; quanto tempo o cavaleiro levou para chegar?». CCA - Em lesões parietais inferiores ou paríeto-occipitais esquerdas há dificuldade em compreender o problema como um todo. A resolução é possível se o problema for dividido em pequenas partes. Dificuldade de reter os elementos verbais do problema pode impossibilitar a resolução dos problemas, como ocorre em lesões temporais esquerdas. Em lesões frontais a análise dos elementos é incorreta, as operações são fragmentadas e não obedecem a um plano lógico.

\section{COMENTARIOS}

Para que o neuropsicólogo compreenda e interprete os distúrbios das atividades nervosas superiores é necessário conhecer as concepções atuais sobre localização de funções no sistema nervoso central. Após a descoberta de Broca, que em 1861 localizou a área responsável pela "imagem motora das palavras", na base do terceiro giro frontal do hemisfério esquerdo, seguiram-se vários estudos que pareciam situar a sede das atividades nervosas complexas em áreas cerebrais circunscritas. Desse modo, no início do século $\mathrm{XX}, \mathrm{o}$ cérebro era imaginado como constituído de um mosaico em que cada área restrita seria responsável por uma função complexa. Evidentemente, essa concepção simplista encontrou inúmeros opositores. De fato, localizar uma função nervosa complexa, como por exemplo a capacidade de cálculo ou a de escrita, numa pequena área cerebral é, no mínimo, implausível ${ }^{1}$. Segundo o conceito de "sistema funcional completo" empregado por Luria, as atividades nervosas complexas dependem do desempenho integrado de diversas áreas corticais $\mathrm{e}$ subcorticais do cérebro. A contribuição de cada região é específica, de modo que sua lesão provocará alteração especifica da atividade nervosa em estudo. Como uma mesma região pode estar integrada a diversos sistemas funcionais, a lesão irá interferir em várias atividades nervosas, afetando-as de uma maneira peculiar. Lefèvre considerava que havia necessidade de se aprofundar os 
conhecimentos sobre a intimidade dos processos cerebrais que participam das atividades nervosas superiores. Lefèvre $3,4,5,6,7$ sempre considerou $o$ roteiro semiológico imprescindível para o neuropsicólogo desvendar os mistérios do cérebro em ação. Seu Exame Neurológico Evolutivo oferece ocasião de aproveitamento de vários itens relativos ao exame da organização acústico-motora, função cinestésica, praxias ideomotoras, construtivas e ideatórias. É preciso lembrar também que a utilização de certos testes psicológicos em pesquisas neurológicas, como referem Lefèvre e Lefèvre 8 , pode decidir sobre a presença ou ausência da doença cerebral, bem como ampliar a observação clinica, pela conjugação de suas técnicas.

Ao estudar as atividades nervosas superiores impõe-se ter sempre presente a noção de que é necessário qualificar o distúrbio e não simplesmente constatá-lo. Será o estudo cuidadoso dos sintomas que levará à sua compreensão numa análise neuropsicológica. Os resultados desse exame qualitativo contribuem não somente para a compreensão do sistema funcional, como também para indicar o melhor caminho no processo de reeducação do paciente.

\section{RESUMO}

Os autores apresentam versão simplificada da investigação neuropsicológica segundo Luria, baseando-se naquela de Christensen. É feita "qualificação" dos sintomas que são associados e correlacionados a estrutura anatômicas cerebrais. segundo o conceito de sistemas funcionais.

\section{SUMMARY}

\section{Neuropsychological semiology.}

The authors present a version of the Luria's neuropsychological investigation from an initial battery comprising all the Luria's items, and according to Christensen. It is not an standardized procedure but the investigation of each area of the brain that can be regarded as a supplement to classical neurology. Each of the areas makes a highly specific contribution to ensure the operation of the functional system.

\section{RHFERENCIAS}

1. Callegaro, D. \& NITRINI, R. - Afasias. In H. M. Canelas, J. L. Assis \& M. Scaff (eds.): Fisiopatologia do Sistema Nervoso. Sarvier, são Paulo, 1983, pg. 383.

2. CHRISTENSEN, A. - Luria's Neuropsychological Investigation. Spectrum, New York, 1975.

3. LEF tre, A.B. - Contribuição para o estudo da psicopatologia da afasia em crianças. Arq. Neuro-Psiquiat. (São Paulo), 8:345, 1950.

4. LEFEVRE, A.B. - Contribuição para a padronização do exame neurológico do recém-nascido normal. Tese. Faculdade de Medicina da Universidade de são Paulo, 1959. 
5. LFFerRF, A.B. - Exame Neurológico Evolutivo. Sarvier, São Paulo, 1972.

6. LEFtrve, A.B. - Disfunçăo Cerebral Mínima. Sarvier, são Paulo, 1975.

7. LEFeVRE, B.H. \& LFF'tVRE, A.B. - Fstudo neuropsicológico da afasia. Apresentaçăo de um caso de criança com afasia pós-traumática. Psicologia, 6:21, 1980.

8. LEFtVRE, B.H. \& LEFRtVE, A.B. - Exame neuropsicológico. In H.M. Canelas, J.L. Assis \& M. Scaff (eđs.): Fisiopatologia do Sistema Nervoso. Sarvier, São Paulo, 1983, pg. 403.

9. LOURANCO FILHO, M.B. - Teste ABC de Maturidade Escolar. Melhoramentos, Såo Paulo, 1952.

10. LURIA, A.R. - Higher Cortical Functions in Man. Basic Books, New York, 1966.

11. LURIA A.R. - Fundamentos de Neuropsicologia. Livros Técnicos e Científicos, Editora da Universidada de São Paulo. Săo Paulo, 1981.

Clinica Neurologica, Hospital das Clinicas, FMUSP - Caixa Postal s461 - 01000, Sdo Parulo, SP - Brasil. 